\title{
UMA VISÃO SENEQUIANA DA AMIZADE
}

\author{
ARIOVALDO AUGUSTO PETERLINI* \\ Faculdade de Filosofia, Letras e Ciências Humanas \\ da Universidade de São Paulo
}

\begin{abstract}
RESUMO: A Antigüidade, num percurso de mais ou menos 900 anos, de Hesiodo a Plutarco, estudou e comentou a amizade, ora de passagem ora em obras especificas como o Laelius de Cícero. Sêneca deixou suas reflexões sobre a amizade, principalmente nas Epistulae ad Lucilium e no De beneficiis. Ao contrário de Platão e Aristóteles, teóricos, Sêneca, romano, pragmático e moralista, volta-se para a amizade em ato. Encontrando dificuldades em conciliar a autarcia do estóico, que era, com sua visão pessoal da amizade, não se recusou a respigar nos campos de Epicuro. Para Sêneca, ao contrário de Aristóteles, é fácil conseguir amigos e substituí-los, quando se vão. Como Cícero, ele também crê que a amizade é a comunhão de virtudes entre os bons, mas não deixa de advertir que quem é amigo de si nunca estará sozinho. Acredita que "quem é amigo ama; mas quem ama nem sempre é amigo". Cumpre, estoicamente, não aceitar nunca desequilibrios emocionais vindos do exterior, ainda que de amigos.
\end{abstract}

PALAVRAS-CHAVE: amizade; Sêneca; estoicismo; autarcia.

Desde o momento em que o homem conseguiu alongar seus olhos para além da comida e da reprodução, entrou a refletir sobre si, sobre seus atos e enveredou para o mundo sublime e terrível das reflexões mais profundas sobre sua existência e natureza, na busca de um sentido para a sua vida. Chegou a muitos lugares, mas até hoje não chegou aonde pretendia e ainda pretende chegar. Vinte e tantos séculos de filosofia acumulados em volumes sem conta pelas bibliotecas e continuamos, nascidos ou não em provetas, a apalpar cegamente o misterioso elefante da verdade.

É claro que o homem e tudo o que lhe diz respeito mais direto constituiu-se sempre no fulcro de interesse da reflexão humana. Ora, a relação entre os homens, o relacionamento com o outro foi objeto perene de estudo, já que a nossa vida se realiza normalmente em grupo, em sociedade e, como se trata de seres racionais, deveria ser consciente. 
Em seu excelente trabalho Philia. La notion d'amitié dans la philosophie antique, Jean-Claude Fraisse examina a philía, esse tipo de relação humana em extremo complexo e belo, desde o phílos homérico, já com o valor de carus, dilectus, já com o de simples possessivo (comparável talvez ao nosso "Esse chapéu é do amigo?") até o pensamento de Plutarco, inspirado, respeito ao assunto, em Aristóteles e no epicurismo. É um caminho longo de mais ou menos 900 anos e 500 páginas, cujo percurso passa mais à ligeira por Hesíodo e Teógnis, pelos pitagóricos, pelos trágicos e historiadores gregos, por Empédocles, pelos sofistas e, com mais vagar filosófico, pelo Lísias de Platão, pela Ética a Nicômaco e pela Ética a Eudemo de Aristóteles, pela amizade e prazer de existir do epicurismo e, depois, pelo que Fraisse chama de "esquecimento e sobrevivência da amizade antiga" (Fraisse, 1974, p. 331) onde se situam o estoicismo, Panécio e o Laelius ou De Amicitia de Cícero e, por fim, Sêneca e Plutarco.

Nessa panorâmica imensa e riquíssima da visão da amizade no pensamento dos antigos, tentaremos apresentar aqui um close humilde e, sem dúvida, limitado das reflexões que Sêneca nos legou e, já que temos as próprias palavras do pensador, cremos que o mais lógico é ouvir o que ele mesmo diz sobre o assunto: aí está a razão dos muitos textos senequianos aqui apresentados; contentar-nos-emos, pois, com a função de iluminador de cena, quando preciso nos parecer.

Platão e Aristóteles, principalmente, desenvolvem suas idéias sobre a amizade, à luz de uma filosofia preocupada com a natureza da philía, e exigem de nós permanência longa no campo teórico, para não dizer metafísico. Sêneca, se despreocupa desse nível de estudo; é um romano pragmático e moralista, voltado para o homem do dia a dia, para a amizade em ato mais que em potência, tão prático que, sendo basicamente um estóico, não se contém que não respigue até nos campos de Epicuro os pensamentos que considera úteis para elucidar o que lhe parece a amizade verdadeira.

As obras de Sêneca que mais nos permitem o estudo de suas idéias sobre a amizade são algumas das 124 Epístolas Morais a Lucilio, os sete livros do tratado Sobre os Benefícios e uns poucos fragmentos de um desaparecido tratado Sobre a Amizade, descobertos em um palimpsesto e publicados por Ângelo Mai, em Roma, em 1820 (Manzamedo, 1966, p. 210). Infelizmente não conseguimos sequer ler esses fragmentos em alguma publicação. Mas acreditamos ter mais que o suficiente para os limites deste trabalho nas Epístolas a Lucilio.

Cumpre lembrar, de início, que o pensamento de Sêneca funda suas bases mestras no Estoicismo e a philia, que os romanos nomearam como amicitia, vista 
pelos estóicos, como diz Jean-Claude Fraisse, diferencia-se da concebida por seus antecessores ou contemporâneos nisso, que a consciência comum não pode ser definida, psicologicamente, como consciência da existência, mas, somente de maneira racional, como consciência da ordem (Fraisse, 1974, p. 372-3).

Ora, é exatamente o princípio estóico da autárkeia (autarcia), do estado de quem se basta a si mesmo, de quem leva em si todos os seus bens, de quem jamais considera como um bem o que lhe pode ser tirado, é precisamente isso o que gera dificuldades a Sêneca na interpretação da amizade como ele a entende, o que o constrange, não raro, embora desmedindo-se em escusas, a valer-se dos ensinamentos de Epicuro. Vez por outra, a fidelidade aos estóicos o leva, a meu ver, a resvalar em contradições. Vejamos alguns textos em que Sêneca tenta conciliar a autárkeia do sábio estóico com a sua visão da amizade.

1. An merito reprehendat in quadam epistula Epicurus eos qui dicunt sapientem se ipso esse contentum et propter hoc amico non indigere, desideras scire. Hoc obicitur Stilboni ab Epicuro et iis quibus summum bonum uisum est animus impatiens [...]. 3. Hoc inter nos et illos interest: noster sapiens uincit quidem incommodum omne sed sentit, illorum ne sentit quidem. Illud nobis et illis commune est, sapientem se ipso esse contentum. Sed tamen et amicum habere uult et uicinum et contubernalem, quamuis sibi ipse sufficiat [...]. 5. Ita sapiens se contentus est, non ut uelit esse sine amico sed ut possit; et hoc quod dico "possit" tale est: amissum aequo animo fert. Sine amico quidem numquam erit; in sua potestate habet quam cito reparet. Quomodo si perdiderit Phidias statuam protinus alteram faciet, sic hic faciendarum amicitiarum artifex substituet alium in locum amissi [...]. 7. Attalus philosophus dicere solebat iucundius esse amicum facere quam habere, "quomodo artifici iucundius pingere est quam pinxisse" [...]. 8. Sapiens etiam si contentus est se, tamen habere amicum uult, si nihil aliud, ut exerceat amicitiam, ne tam magna uirtus iaceat, non ad hoc quod dicebat Epicurus in hac ipsa epistula, "ut habeat qui sibi aegro adsideat, succurrat in uincula coniecto uel inopi", sed ut habeat aliquem cui ipse aegro adsideat, quem ipse circumuentum hostili custodia liberet. Qui se spectat et propter hoc ad amicitiam uenit male cogitat (Ad Lucilium, I, 9)

1. Desejas saber se assiste razão a Epicuro, quando em uma carta sua reprova aqueles que dizem que o sábio consigo mesmo se contenta e por isso não precisa de amigo. Epicuro objeta isso a Estilbão e àqueles aos quais o sumo bem parece consistir na impassibilidade do espírito [...]. 3. Existe entre nós e eles esta diferença: o nosso sábio vence 
realmente qualquer contrariedade, mas a sente; o deles nem sequer a sente. Nós e eles temos isto em comum, que o sábio consigo mesmo se contenta. Mas, embora baste a si mesmo, quer ter um amigo, um vizinho um companheiro de estudo [...]. 5. Assim o sábio basta a si mesmo, não no sentido de que queira estar sem amigo, mas no de que pode fazê-lo; e quando digo "pode", quero dizer que suporta com serenidade a perda de um amigo. Nunca ficará realmente sem amigo; em seu poder está reparar de imediato a falta.Da mesma forma que se Fídias perdesse uma estátua, faria outra em seguida, assim este artista em fazer amizades substituirá por outro o amigo perdido [...]. 7. O filósofo Átalo costumava dizer que é mais agradável fazer um amigo do que tê-lo, "como ao artista é mais agradável pintar do que ter pintado" [...]. 8. O sábio, mesmo se basta a si próprio, quer, todavia, ter um amigo, se não por outra razão, ao menos para exercitar a amizade, não vá tão importante virtude ficar sem cultivo; e não com o objetivo que Epicuro declarava nessa mesma carta, "para que alguém tenha quem o assista, se está doente; socorra, se lançado na prisão ou se está necessitado”, mas para que tenha alguém a quem, se doente, ele próprio assista, a quem ele mesmo resgate, se prisioneiro de um inimigo. Quem só a si mesmo vê e com tal objetivo busca uma amizade, pensa erradamente.

Fica patente, a partir daí, que a verdadeira amizade, para os estóicos, para Sêneca, se dá entre os sábios. Aristóteles afirmara já, na Ética a Nicômaco, que a amizade legítima só pode acontecer entre os bons, entre os que se assemelham pela virtude; pode haver prazer na amizade, mas não é dele que ela deve nascer, senão da virtude. Assim os homens honestos só devem procurar amigos entre os virtuosos, já que, cada um, ao conseguir o bem do outro, alcança o próprio bem; donde poder dizer-se que a amizade é igualdade. Todavia, esse "próprio bem" não é a razão de ser da amizade; Aristóteles situa o fundamento da amizade na gratuidade. Assevera ele que, atenta a perfeição que a reciprocidade entre os amigos deve atingir, ela não pode ser dada a mais de um: pode-se agradar a muitos e ter sentimentos agradáveis em relação a muitos, mas o bem da amizade propriamente dito não pode ser multiplicado. As grandes amizades se limitam a um só amigo e tão rara é a verdadeira amizade, que pode dar-se por extremo feliz quem conseguir ao menos um amigo (Gobry, 1995, p. 85-7. 90).

Em comparação desse conceito aristotélico, a amizade proposta por Sêneca é algo bem menos profundo, mais normativo, já, talvez, pela sobrecarga da autárkeia de fonte estóica, que aliás, no tocante à amizade, Sêneca tem a ousadia de batizar com um pouco da sensibilidade proposta por Epicuro, já, ainda talvez, por ter 
vivido tanto em meio às desconfianças da corte de Nero, que, de ora em onde, a par com as afirmações de confiança total que o amigo deve ter no amigo, deixa entrever certo resguardo nas emoções capazes de magoar o que confia de peito aberto. Por outro lado, enquanto o amigo de Aristóteles é dificílimo de encontrar, o sábio de Sêneca não tem dificuldade alguma em conseguir, não um amigo, mas vários amigos e, mestre que é em fazer amigos, é capaz de substituí-los facilmente, quando os perde...

Examinemos, a seguir, mais umas passagens da obra de Sêneca para "ouvilo" em suas próprias palavras:

12. "Quomodo ergo ad illam accedit?" Quomodo ad rem pulcherrimam, non lucro captus nec uarietate fortunae perterritus; detrahit amicitiae maiestatem suam qui illam parat ad bonos casus. 13. [...] se contentus est sapiens ad beate uiuendum, non ad uiuendum; ad hoc enim multis illi rebus opus est, ad illud tantum animo sano et erecto et despiciente fortunam [...].15. Ergo quamuis se ipso contentus sit, amicis illi opus est; hos cupit habere quam plurimos, non ut beate uinat; uiuet enim etiam sine amicis beate. Summum bonum extrinsecus instrumenta non quaerit; domi colitur, ex se totum est; incipit fortunae esse subiectum si quam partem sui foris quaerit [...].17. Ad amicitiam fert illum nulla útilitas sua, sed naturalis inritatio; nam ut aliarum nobis rerum innata dulcedo est, sic amicitiae. Quomodo solitudinis odium est et adpetitio societatis, quomodo hominem homini natura conciliat, sic inest huic quoque rei stimulus qui nos amicitiarum adpetentes faciat. Nihilominus cum sit amicorum amantissimus, cum illos sibi comparet, saepe praeferat, omne intra se bonum terminabit et dicet quod Stilbon ille dixit, Stilbon quem Epicuri epistula insequitur. Hic enim capta patria, amissis liberis, amissa uxore, cum ex incendio publico solus tamen beatus exiret, interroganti Demetrio, cui cognomen ab exitio urbium Poliorcetes fuit, num quid perdidisset, "omnia", inquit, "bona mea mecum sunt" [...]. 19. Ecce uir fortis ac strenuus! ipsam hostis sui uictoriam uicit. "Nihil", inquit, "perdidi": dubitare illum coegit an uicisset. "Omnia mea mecum sunt": iustitia, uirtus, prudentia, hoc ipsum, nihil bonum putare quod eripi possit (Ad Lucilium, I, 9)

12. "Como, pois, chega até ela?" Como a uma coisa belíssima, não dominado pelo lucro, nem aterrorizado pela instabilidade da fortuna; tira à amizade a sua nobreza quem se esforça para obtê-la, visando às ocasiões vantajosas. 13. [...] O sábio basta a si mesmo para viver feliz, não para viver; para isso tem ele, na verdade, precisão de muitas 
coisas; para aquilo, somente de um espírito sensato, elevado e desdenhoso da fortuna [...]. 15. Portanto, embora baste a si mesmo, tem necessidade de amigos; deseja tê-los no maior número possível, não para viver feliz; viverá feliz, em verdade, também sem amigos. $\mathrm{O}$ sumo bem não busca fora de si os meios de realizar-se; cultiva-se em casa, faz-se inteiro de si mesmo; começa a ficar à mercê da sorte, se busca fora alguma parte de si [...]. 17. Impele-o à amizade não qualquer utilidade pessoal, mas um estímulo natural; como temos uma agradável atração por outras coisas, assim também, pela amizade. Como há o ódio à solidão e o desejo de companhia, como a natureza aproxima o homem ao homem, assim tem ela também um estímulo que nos faz desejosos de amizades. Contudo, ainda que (o sábio) tenha o maior afeto pelos amigos, ainda que os considere como a si mesmo, porá dentro de si o limite de todo o bem e repetirá aquilo que disse Estilbão, aquele Estilbão que a carta de Epicuro reprova. Ele, tomada a sua cidade natal, perdidos os filhos, perdida a esposa, ao sair sozinho mas feliz do incêndio geral, respondeu a Demétrio, que teve seu cognome de Poliorcetes tirado da destruição de cidades, o qual lhe perguntava se tinha perdido alguma coisa: "Todos os meus bens estão comigo" [...]. 19. Eis um homem forte e corajoso! Venceu a própria vitória de seu inimigo: "Não perdi nada", disse ele. Obrigou o outro a duvidar se tinha vencido. "Todos os meus bens estão comigo": a justiça, a virtude, a prudência e principalmente esse "não considerar como um bem o que pode ser tirado".

Ecoando, por certo, Panécio, um estóico, Cícero põe como a mais importante e segura de todas as sociedades humanas a que nasce entre os homens de bem que se ligam assim pelas virtudes como pelo caráter semelhante, a amizade. Nada cria vínculos mais estreitos que a similitude dos bons costumes, diz Cícero. Existem as mesmas tendências e as mesmas aspirações e isso faz que um no outro se compraza, compondo de duas almas uma só, coisa que Pitágoras considerava o ápice da amizade. Não deixa de ser importante também o laço originado dos benefícios reciprocamente dados e recebidos (Cícero, De Officiis, XVII, 55-6).

Essa afinidade de virtude, de saber e de ideais aparece também na visão senequiana da amizade; todo o progresso no aperfeiçoamento pessoal, quer de caráter, quer na sabedoria, é praticamente estéril e inútil, se aferrolhado no estreito da própria solidão do indivíduo incapaz de repartir. Todavia, após essas afirmações, merece especial atenção o, ao meu ver, pé atrás inconsciente do estóico, no epílogo da carta I, 6, de que extraímos as passagens abaixo. 
2. Cuperem itaque tecum communicare tam subitam mutationem mei; tunc amicitiae nostrae certiorem fiduciam habere coepissem, illius uerae quam non spes, non timor, non utilitatis suae cura diuelit, illius cum qua homines moriuntur, pro qua moriuntur. 3. Multos tibi dabo qui non amico sed amicitia caruerint: hoc non potest accidere cum animos in societatem honesta cupiendi par uoluntas trahit. Quidni non possit? Sciunt enim ipsos omnia habere communia, et quidem magis aduersa. 4. [...] nec me ulla res delectabit, licet sit eximia et salutaris, quam mihi uni sciturus sum. Si cum hac exceptione detur sapientia, ut illam inclusam teneam nec enuntiem, reiciam: nullius boni sine socio iucunda possessio est [...]. 7. Interim quoniam diurnam tibi mercedulam debeo, quid me hodie apud Hecatonem delectauerit dicam. "Quaeris", inquit, "quid profecerim? amicus esse mei coepi." Multum profecit: numquam erit solus. Scito esse hunc amicum omnibus (Ad Lucilium, I, 6)

2. Desejaria, por isso, inteirá-lo desta minha tão repentina mudança; então começaria a ter uma fé mais segura em nossa amizade, essa verdadeira amizade que nem a esperança, nem o temor, nem a preocupação do próprio interesse rompem; essa amizade com que os homens morrem e pela qual morrem. 3. Muitos te citarei que careceram não de amigo, mas da amizade: isso não pode acontecer quando uma vontade irmã atrai as almas para uma união desejosa do bem. E por que não seria possível? Sabem que eles próprios têm em comum todas as coisas, principalmente as adversas. 4. [...] nem coisa alguma, ainda que excelente e útil, me trará agrado, se hei de sabê-la só para mim. Se me fosse dada a sabedoria, com a condição de que a mantivesse escondida e não a comunicasse, eu a rejeitaria. A posse de nenhum bem traz alegria, sem um companheiro [...]. 7. Entretanto, já que te devo meu pequeno presente de cada dia, direi o que hoje me agradou em Hecatão: "Perguntas-me", diz, "em que progredi? Comecei a ser amigo de mim mesmo.” Progrediu muito: nunca estará sozinho. Fica sabendo que todos têm esse amigo.

Se a confiança no amigo é essencial, cumpre para isso conhecer a preceito o valor, a virtude, a sabedoria daquele a quem nos conduz um princípio de amizade. Os homines boni não devem buscar amigos senão entre seus semelhantes. Assim pensava já Aristóteles, que a verdadeira amizade só pode existir entre os honestos (Gobry, 1995, p. 85). "Ouçamos" o próprio Sêneca.

1. Epistulas ad me perferendas tradidisti, ut scribis,amico tuo; deinde admones me ne omnia cum eo ad te pertinentia communicem, quia non soleas ne ipse quidem id facere: ita eadem epistula illum et dixisti amicum 
et negasti [...]. 2. Sed si aliquem amicum existimas cui non tantumdem credis quantum tibi, uehementer erras et non satis nosti uim uerae amicitiae. Tu uero omnia cum amico delibera, sed de ipso prius: post amicitiam credendum est, ante amicitiam iudicandum. Isti uero praepostero officia permiscent qui,contra praecepta Theophrasti, cum amauerunt iudicant, et non amant cum iudicauerunt. Diu cogita an tibi in amicitiam aliquis recipiendus sit. Cum placuerit fieri, toto illum pectore admitte; tam audaciter cum illo loquere quam tecum. 3. Tu quidem ita uiue ut nihil tibi committas nisi quod committere etiam inimico tuo possis; sed quia interueniunt quaedam quae consuetudo fecit arcana, cum amico omnes curas, omnes cogitationes tuas misce. Fidelem si putaueris, facies; nam quidam fallere docuerunt dum timent falli, et illi ius peccandi suspicando fecerunt [...]. 4. [...] utrumque enim uitium est, et omnibus credere et nulli, sed alterum honestius dixerim uitium, alterum tutius (Ad Lucilium, I, 3)

1. Entregaste, como escreves, a um teu amigo as cartas para que me fossem trazidas; em seguida me advertes que não lhe comunique todos os assuntos que te dizem respeito, porquanto nem tu próprio estás habituado a fazer isso: assim, na mesma carta, afirmaste e negaste que ele é teu amigo [...]. 2. Mas se consideras amigo alguém em quem não confias tanto quanto em ti mesmo, erras gravemente e ignoras o valor da verdadeira amizade. Tu, então, delibera sobre tudo com o amigo, mas antes delibera sobre ele próprio: depois da amizade, deve-se confiar nele; antes da amizade, cumpre avaliá-lo. Confundem, porém, os deveres da amizade, invertendo a ordem, aqueles que, contra os preceitos de Teofrasto, depois de se afeiçoarem, julgam, e rompem a afeição, depois de julgar. Reflete por longo tempo se alguém deve ser por ti eleito como amigo. Quando parecer bem que tal se faça, aceita-o de todo o coração; fala com ele como se falasses contigo mesmo.3. E tu vive de tal maneira que não confies a ti mesmo senão o que possas confiar até a teu inimigo; mas como existem algumas coisas que o costume tornou particulares, compartilha com o amigo todas as preocupações, todos os teus pensamentos. Se o considerares fiel, tu o farás fiel, pois alguns, temendo ser enganados, ensinaram a enganar e eles, suspeitando, criaram o direito de trair [...]. 4. [...] é defeito uma e outra coisa, tanto fiar-se de todos quanto de ninguém, mas diria que o primeiro defeito é mais honesto e o segundo, mais seguro.

Apesar da declaração de que visar à amizade com o fito no útil é esvaziar de sua essência a mesma amizade, Sêneca está que, se um dos amigos não busca o seu 
próprio aperfeiçoamento, não resta motivo para continuar amigo. No excerto que vamos ler, sobre deixar patente essa sua visão um tanto utilitarista da amizade, em que pese aí à nobreza do útil, Sêneca acredita que o amigo leva as lampas ao amante...

1. Cum te ualde rogo ut studeas, meum negotium ago: habere amicum uolo, quod contingere mihi nisi pergis ut coepisti excolere te, non potest. Nunc enim amas me, amicus non es. "Quid ergo? haec inter se diuersa sunt?" immo dissimilia. Qui amicus est amat; qui amat non utique amicus est; itaque amicitia semper prodest, amor aliquando etiam nocet (Ad Lucilium, IV, 35)

1. Quando com tanta insistência te peço que estudes, faço-o em meu próprio interesse: quero ter um amigo e isso não me pode acontecer, a menos que continues a aperfeiçoar-te como principiaste. Agora tu me amas, mas não és meu amigo. "Por que isso? São diversas entre si essas duas coisas?" Não são nem mesmo semelhantes. Quem é amigo, ama; mas quem ama nem sempre é amigo. Assim é que a amizade sempre aproveita, mas o amor, às vezes, até prejudica.

Como já pudemos vislumbrar nos vários trechos das cartas de Sêneca que vimos lendo, a preocupação estóica de não se permitir qualquer desequilíbrio emocional é cuidado constante da razão fiscalizadora das emoções movidas do exterior, mesmo da amizade. Chega a estranhar-nos a facilidade com que Sêneca reprova a dor excessiva pela perda de um amigo; afinal, há outros!...

1. Nec sicci sint oculi amisso amico nec fluant; lacrimandum est, non plorandum [...]. 8. Ideo amicis auide fruamur quia quamdiu contingere hoc possit incertum est [...]. 10. Si habemus alios amicos, male de iis et meremur et existimamus, qui parum ualent in unius elati solacium; si non habemus, maiorem iniuriam ipsi nobis fecimus quam a fortuna accepimus: illa unum abstulit, nos quemcumque non fecimus. 11. Si quis despoliatus amissa unica tunica conplorare se malit quam circumspicere quomodo frigus effugiat et aliquid inueniat quo tegat scapulas, nonne tibi uideatur stultissimus? Quem amabas extulisti: quaere quem ames. Satius est amicum reparare quam flere (Ad Lucilium, VII, 63)

1. Não fiquem secos os nossos olhos pela perda de um amigo, mas nem se inundem; deve-se derramar algumas lágrimas, não afligir-se em demasia [...] 8. Usufruamos, portanto, avidamente dos amigos, porque é incerto por quanto tempo possa isso acontecer [...]. 10. Se 
temos outros amigos, nós nos portamos mal com eles e os consideramos de somenos, já que pouco valem para consolar-nos da perda de um só. Se não os temos, nós nos impusemos a nós próprios dano maior do que o que recebemos do destino: ele nos tirou apenas um amigo e nós, todos aqueles que não conquistamos. 11. Se alguém esbulhado, perdida a única túnica, preferisse lamentar-se a olhar à volta buscando como fugir ao frio e como encontrar algo com que cobrir as costas, não te pareceria em extremo imbecil? Levaste ao túmulo quem amavas: busca a quem possas amar. É melhor conseguir de novo um amigo do que chorar.

A comunhão de todas as coisas entre os amigos, idéia que vem já da máxima de Pitágoras: "Entre os amigos tudo é comum", também Sêneca a dá como característica da verdadeira amizade; deixa, todavia, bem claro o que por isso entende: comuns hão de ser os segredos, as alegrias, as tristezas e... até os bens materiais; mas tem o cuidado de ressalvar que tudo quanto o amigo possui nos é comum, porém ele é quem conserva a propriedade; não se pode fazer uso disso ou vendê-lo contra sua vontade, como não se pode vender o assento do teatro, embora seja comum a nós e a todos os espectadores... (Sêneca, De Beneficiis, VII-XII). Dessa comunidade de bens, principalmente espirituais, é que Sêneca nos fala na seguinte passagem:

2. Iterum ego tamquam Epicurus loquor? mihi uero idem expedit quod tibi: aut non sum amicus, nisi quidquid agitur ad te pertinens meum est. Consortium rerum omnium inter nos facit amicitia; nec secundi quicquam singulis est nec aduersi; in commune uiuitur. Nec potest quiquam beate degere qui se tantum intuetur, qui omnia ad utilitates suas conuertit: alteri uiuas oportet, si uis tibi uiuere. Haec societas diligenter et sancte obseruata, quae nos homines hominibus miscet et iudicat aliquod esse commune ius generis humani, plurimum ad illam quoque de qua loquebar interiorem societatem amicitiae colendam proficit; omnia enim cum amico communia habebit qui multa cum homine (Ad Lucilium, V, 48)

2. Mas eu estou falando ainda como Epicuro? A mim, na verdade,convém o que convém a ti: ou não seria um amigo, se não fosse também meu seja lá o que for que se refira a ti. A amizade cria entre nós a comunhão de todas as nossas coisas; nem algo existe de favorável nem de adverso para um só de nós; vive-se em comum. Não pode viver feliz alguém que só para si tem olhos, que tudo converte a seu próprio benefício: é preciso que viva para outro, quem quiser viver para si. Esta solidariedade cuidadosa e lealmente obser- 
vada, que a nós homens nos une aos outros homens e que confirma haver um direito comum para o gênero humano, contribui também muito para cultivar aquela sociedade mais íntima de que eu falava, a amizade; quem tem muitas coisas em comum com qualquer homem, terá todas em comum com o amigo.

No que tange à amizade pelos que não nos são iguais, como os superiores hierárquicos ou os considerados inferiores, os escravos, é clara a posição de Sêneca.

Em relação aos poderosos, os senadores de maior prestígio ou aqueles a quem o povo entregou o poder sobre o próprio povo, são os seguintes os conselhos de Sêneca:

7. Hos omnes amicos habere operosum est, satis est inimicos non habere. Itaque sapiens numquam potentium iras prouocabit, immo [nec] declinabit, non aliter quam in nauigando procellam [...] 8. [...] sapiens: nocituram potentiam uitat, hoc primum cauens, ne uitare uideatur; pars enim securitatis et in hoc est, non ex professo eam petere, quia quae quis fugit damnat (Ad Lucilium, II, 14)

7. Ter a esses por amigos seria muito trabalhoso; já é bastante não têlos como inimigos. Desta sorte, o sábio nunca provocará as iras dos poderosos; pelo contrário, até as evitará, como se evita, ao navegar, a tempestade [...] 8. [...] o sábio; evita o poder que está pronto para prejudicar, mas tomando, antes de tudo, o cuidado de que não pareça estar evitando; uma parte da segurança está nisto, em não buscála abertamente, porque quem foge condena aquilo de que foge.

Respeito aos escravos, a posição de Sêneca é digna da nossa máxima admiração, porquanto rara num homem de sua posição naquela época. Mas daí a achar que a palavra "amigo" por ele usada com referência a escravos, nas Epístolas 3 e 6 do livro I, tem o mesmo valor da que Sêneca usa com relação ao sábio, erro que nos parece ter cometido Marcos Manzanedo (Manzanedo, 1966, p. 214), não é coisa aceitável. Examinemos alguns trechos de Sêneca sobre o assunto:

1. "Serui sunt!" Immo homines. "Serui sunt!" Immo contubernales. "Serui sunt!" Immo humiles amici. [...] 13. Viue cum seruo clementer, comiter quoque, et in sermonem illum admitte et in consilium et in conuictum. [...] 16. Non est, mi Lucili, quod amicum tantum in foro et in curia quaeras: si diligenter adtenderis, et domi inuenies (Ad Lucilium, V, 47) 
1. "São escravos!" Mas antes são homens. "São escravos!" Mas até vivem sob o mesmo teto. "São escravos!" Mas são humildes amigos. [...] 13. Vive de modo clemente com teu escravo e também com cordialidade; admite-o na conversação, nas deliberações e na mesa. [...] 16. Não há, ó meu Lucílio, por que buscares um amigo apenas no foro ou no senado: se estiveres bem atento, encontrá-lo-ás também em casa.

Pelo contexto, que aqui não damos, Sêneca se refere, nessa última passagem, aos escravos como os amigos que podem ser encontrados em casa. Ora, se lembrarmos que a amizade proposta por Sêneca como verdadeira exige uma troca de aperfeiçoamentos entre sábios, um relacionamento entre iguais, fica evidente que o "amigo" desses textos não é unívoco, mas tem sentidos, se não diferentes, no máximo análogos.

Merece lembrada aqui a bela apologia que Sêneca faz da carta como instrumento de encontro com o amigo ausente:

1. Quod frequenter mihi scribis gratias ago; nam quo uno modo potes te mihi ostendis. Numquam epistulam tuam accipio ut non protinus una simus. Si imagines nobis amicorum absentium iucundae sunt, quae memoriam renovant et desiderium (absentiae) falso atque inani solacio leuant, quanto iucundiores sunt litterae, quae uera amici absentis uestigia, ueras notas adferunt? Nam quod in conspectu dulcissimum est, id amici manus epistulae impressa praestat, agnoscere (Ad Lucilium, IV, 40)

1. Sou-te grato por me escreveres freqüentemente, pois tu te mostras a mim da única maneira que podes. Nunca recebo uma carta tua sem que, no mesmo instante, estejamos juntos. Se os retratos dos amigos ausentes nos são agradáveis, já que renovam a lembrança e aliviam a saudade com enganador e fictício consolo, quão mais agradável nos é a carta que nos traz os verdadeiros vestígios do amigo ausente, sua verdadeira caligrafia. Com efeito, aquilo que é o mais doce na presença de um amigo, reconhecê-lo pelos sentidos, isso a mão do amigo impressa na carta no-lo proporciona.

Sobre o dever de sacrificar-se alguém dolorosamente por um amigo, pelo menos enquanto indivíduo, pessoa, nem os estóicos, nem Cícero, nem Sêneca se pronunciaram claramente. Em Cícero, a pátria ou a humanidade como um todo até poderiam merecer tal devotamento... 
Quanto a Sêneca, se é verdade, como diz Fraisse (Fraisse, 1974, p. 370), "que o humanismo estóico, tal ao menos como resulta da doutrina mais constante da escola, postos de lado certos arranjos do médio estoicismo, parece capaz de estabelecer mais relações de direito que relacionamentos propriamente amigáveis ou afetuosos, com interesse pelo indivíduo", então Sêneca, dentro da idéia bem pragmática e romana de que muito mais importantes são as normas do bem viver do que os princípios teóricos que alicerçam o aperfeiçoamento moral, reflexão que, aliás, já é bastante perceptível em Panécio, então Sêneca, repito, foge consideravelmente à relativa despreocupação estóica com o outro indivíduo, amigo que seja. Estamos longe do enfoque platônico do Lísias, da visão aristotélica das Éticas a Nicômaco (VIII e IX) e a Eudemo (VII), mas muito próximos da vida real, apesar do princípios estóicos que acorrentam o autor das Cartas Morais a Lucílio e não obstante a desconfiança terrivel do mundo de máscaras da corte de Nero, ambiente constante de boa parte de sua vida.

Não há comparar as obras de Sêneca com a elevação metafísica dos tratados gregos, mas elas são bem mais acessíveis ao homem de cultura normal, ansioso de entender e viver as coisas da vida.

\section{Nota}

* Professor Doutor de Língua e Literatura Latina do Programa de Pós-Graduação em Letras Clássicas da FFLCH-USP.

\section{REFERÊNCIAS BibliográficAs}

CICERONE. I Doveri. Milano: Rizzoli Editore, 1987.

FRAISSE, J.-C. Philia. La notion d'amitié dans la philosophie antique. Paris: Librairie Philosophique J. Vrin, 1974.

GOBRY, I. La philosophie pratique d'Aristote. Lyon: Presses Universitaires de Lyon, 1995.

MANZANEDO, M. F. La amistad humana, vista por Seneca. In: -. Estudios sobre Seneca. Madrid: Instituto Luis Vives de Filosofia, 1966. p. 209-19.

SENECA. Lettere a Lucilio (Epistularum Moralium ad Lucilium Libri). Milano: Rizzoli Editore, 1985

SÉNĖQUE. Des Bienfaits. Paris: "Les Belles Lettrres", 1926-7. 
PETERLINI, Ariovaldo Augusto. Une vision sénéquienne de l'amitié.

RÉSUMÉ: L'Antiquité, au cours d'une période de 900 ans plus ou moins, d'Hésiode à Plutarque, a étudié et commenté l'amitié, soit en passant soit dans des oeuvres spécifiques comme le Laelius de Cicéron. Sénèque nous a laissé ses réflexions sur l'amitié, surtout dans les Epistulae ad Lucilium et dans le De beneficiis. Contrairement à Platon et Aristote, tous deux théoriciens, Sénèque, romain, pragmatique et moraliste, s'interesse à l'amitié en acte. Étant données les difficultés qu'il avait pour les concilier, l'autarcie du stoïcien qu'il était et as vision personelle de l'amitié, il ná pas hésité à glaner dans les champs d'Épicure. Pour Sénèque, à l'opposé d'Aristote, il est facile de se faire des amis et de les remplacer, quand ils s'en vont. Comme Cicéron, il croit aussi que l'amitié est la communion de vertus entre les gens de bien, mais il n'oublie pas de souligner que qui est ami de soit même ne sera jamais seul. Il pense que "qui est un ami, aime; mais qui aime n'est pas toujours un ami". Il faut, stoïquement, ne jamais accepter les déséquilibres venant de l'extérieur, quand bien même ils viendraient d'amis.

MOTS-CLÉS: amitié; Sénèque; stoicisme; autarcie. 